\title{
Study on Primary Closure versus Intraoperative CBD Stenting after Choledocholithotomy
}

\author{
HESHAM A. REYAD, M.D.; MOHAMMED K. EWAIS, M.D. and MAGDY A. OMRAN, M.Sc. \\ The Department of General Surgery, Faculty of Medicine, Assiut University, Assiut, Egypt
}

\begin{abstract}
Background: This study aimed to compare intraoperative Common Bile Duct (CBD) stenting with Primary Closure (PC) after choledocholithotomy as regard safety, feasibility, post-operative outcome and complications.

Patients and Methods: This study has been done at Assiut University Hospital in General Surgery Department in the period between 1 st January 2016 to 30 June 2017 including patients with CBDS and failed extraction of stones by Endoscopic Retrograde Cholangiopancreatography (ERCP) and candidates for CBD exploration.
\end{abstract}

Results: The study included 30 patients assigned to 2 groups, Group (A) primary closure and Group (B) intraoperative CBD stenting after choledocholithotomy, each group formed of 15 patients. There were no significant differences between two groups as regard the demographic characteristics. In Group (A) abdominal pain was reported in 3 cases vs. 7 cases in Group (B) and acute pancreatitis in no case vs. 2 cases in Group (B) and cholangitis in no case vs. 1 case in Group (B). As regard pre-operative biological character Group (A) was reported leukocytosis in 3 cases vs. 7 cases in Group (B), $p=0.021$. In Group (A) CBD diameter was $16 \pm 3 \mathrm{~mm}$ vs. $13 \pm 2$ in Group (B). The operation time was $120 \pm 28$ in Group (A) vs. $125 \pm 20$ in Group (B).

About $53 \%$ of cases in Group (A) has been done laparoscopicaly vs. $13 \%$ in Group (B). The hospital stay in Group (A) was $4 \pm 1.5$ vs. $2 \pm 0.5$ days in Group (B) Six cases of Group (A) experienced bile leakage vs. 2 cases in Group (B). Four cases of Group (A) were reported to have wound infection vs. 2 cases in Group (B).

Conclusion: Intraoperative CBD stenting is a safe and feasible method after choledocholithotomy in cases of CBDS after failure of their extraction by ERCP.

Key Words: Choledochotomy - Common bile duct stones Laparoscopic - Primary closure - CBD stenting.

\section{Introduction}

GALLSTONE disease is a major cause of morbidity world-wide. The prevalence of gallstone disease varies around the world [1]. About 5-15\%

Correspondence to: Dr. Magdy A. Omran, E-Mail: drmagdy25@y ahoo.com of patients with symptomatic gallstones have common bile duct stones at the time of surgery, the portion grow with increasing age and duration of symptoms [2]. CBDS require extraction to avoid complications, such as acute suppurative cholangitis, obstructive jaundice, hepatic abscess, and acute pancreatitis [3]. There is no standard treatment today. In principle, three treatment regimens are available; endoscopic stone extraction during ER$\mathrm{CP}$, laparoscopic bile duct exploration [4], and open exploration. There is no strong evidence from controlled trials that one procedure is superior to another in experienced hands. If stone extraction is performed by the transcholedochal approach, the surgeon has 2 main options for choledochotomy management: Primary closure, or closure after biliary stenting.

\section{Patients and Methods}

This study has been done at Assiut University Hospital in General Surgery Department in the period between 1 st January 2016 to 30 June 2017 including patients with CBDS and failed extraction of stones by ERCP and candidates for common bile duct exploration either open or laparoscopicaly. The 30 patients were randomly assigned to two groups: Primary closure group $(\mathrm{n}=15)$ and intraoperative CBD stenting group $(n=15)$. Informed consent was requested from all the patients involved.

\section{Surgical technique:}

Right subcostal or upper middle-line incision. The hepatoduodenal ligament is stretched by pulling up the quadrate lobe using a retractor and pulling

\section{Abbreviations:}

CBD : Common Bile Duct.

ERCP : Endoscopic Retrograde Cholangiopancreatography. PC : Primary Closure. 
down the pancreatic head by using the assisting surgeon's hand. After the gallbladder has been removed, 'Kocherise' the duodenum. Next, open the peritoneum to expose the CBD above the first part of the duodenum. Place two stay sutures at the level of the mid-portion of the CBD. Using a pointed scalpel and a Pott's right-angled scissors open the CBD vertically about $2 \mathrm{~cm}$. Bile, and maybe stones, will spill out through the opening. From below, with fingers behind the duodenum and head of the pancreas, milk the CBD and retrieve stones as they emerge from the choledochotomy. Stones in the CBD can be extracted using Desjardins forceps or a Fogarty balloon catheter. Then pass a small sized plastic catheter (8-10-12fr) through the choledochotomy in the CBD until it is palpated in the duodenum to confirm the patency of the CBD in order to avoid the usage of the metalic dilators also the catheter used for, flushing of the CBD with saline to expel a small retained stones and also to do intraoperative cholangiogram [5]. A flexible choledochoscope allows visualisation of the common hepatic duct and its major branches proximally, and the CBD to the sphincter distally to confirm duct clearance. Then primary closure of CBD can be done with interrupted 3/0 vicrel sutures [6].

But for cases of intraoperative CBD stenting The same steps as primary closure but before closure of the CBD we put aplastic stent in the duct through the choledochotomy [7]. You should palpate the distal end of the stent in the duodenum to insure that the stent in its correct place. Then close the duct with interrupted $3 / 0$ vicrel sutures. A drain is placed in the subhepatic region and brought out through a separate stab incision.

\section{Discharge and follow-up:}

Patients resumed diet gradually post-operative. Follow-up liver function test, jaundice, color of urine, temperature, abdominal examination, wound infection and abdominal US before removal of drains and discharge. After discharge follow-up done after one week then after six weeks for removal of the stent for cases of intraoperative CBD stenting if the stent not based spontaneously. Then follow-up every six months for recurrent CBD stones or biliary stricture.

\section{Statistical analysis:}

Categorical variables were presented as count and percentage, and the statistical difference between the two groups was determined by chi-square testing. Continuous variables were expressed as mean \pm Standard Derivation (SD) and comparisons of data were performed with Student's $t$-test. Statistical significance was determined by a $p$-value less than 0.05 .

\section{Results}

Thirty patients fulfilling the inclusion criteria were included in the study. The following are the results of the study, regarding demographic characters, clinical characters, pre-operative biological characters, pre-operative radiological characters, intraoperative characters, post-operative characters and complications.

\section{1-Demographic characters:}

There is no significant difference in both groups regarding the demographic characters as shown in Table (1).

\section{2- Clinical characters:}

There are three cases (20\%) of Group (A) were complaining from abdominal pain due to acute cholecystitis versus seven cases (46\%) in Group (B) due to acute cholecystitis in four cases, acute pancreatitis in two cases and cholangitis in one case. fourteen cases (93\%) in Group (A) had jaundice versus thirteen (86\%) in Group (B) as shown in Table (2).

\section{3- Pre-operative biological characters:}

In cases of primary closure of CBD after choledocholithotomy, three cases (20\%) had preoperative leukocytosis which mostly due to acute cholecystitis, on the other hand seven cases (46\%) who had done closure over stent, had leukocytosis due to acute cholecystitis, acute pancreatitis or cholangitis. $p$-value was 0.021 which is statistically significant. Other preoperative biological characters are statistically insignificant as shown in Table (3).

\section{4- Pre-operative radiological characters:}

As regard the preoperative radiological characters, CBD diameter in cases of PC was (11-22) $\mathrm{mm}$ vs. (8-18) $\mathrm{mm}$ in cases of closure over stent. As regard the number of stones, it was multiple stones in ten cases (66\%) of Group (A), but in Group (B) twelve (80\%) of them had multiple stones. Regarding the size of stones, twelve of cases $(80 \%)$ of Group (A) had large sized stones $(\geq 1 \mathrm{~cm})$, on the other hand eleven of cases $(73 \%)$ of Group (B) had large sized stones. Pre-operative ERCP was done for all cases of CBD stones, thirteen of cases $(86 \%)$ do primary closure, preoperative stent insertion had been done but canulation and stenting had been failed for others due to atrophic or small sized papillae. But in cases un- 
derwent closure over stent ,canulation and stenting had been done for twelve of them $(80 \%)$ as shown in Table (4).

\section{5- Intraoperative characters:}

As regard the intraoperative characters, eight of cases (53.3\%) of Group (A) had been done laparoscopicaly until the end of the procedure. Three of them started laparoscopicaly, but turn to open due to unclear anatomy, the other four cases had been done by open surgery from the start. But for Group (B) thirteen of them $(86.6 \%)$ had been done by open surgery, and the rest two cases by laparoscopy.

The operation time for Group (A) was from 90 to 135 minutes, but for Group (B) was from 100 to 145 minutes. All cases had complete CBD clearance and intraoperative abdominal drain as shown in Table (5).

\section{6-Post-operative characters:}

As shown in Table (2) the median post-operative hospital stay was shorter in Group (B) $2 \pm 0.5$ (23 days) than in Group (A) $4 \pm 1.5$ (3-7 days) with $p$-value $=0.043$, which is statistically significant. In cases of PC six of patients $(40 \%)$ experienced post-operative bile leakage, three of them improved by conservative treatment, but the other three cases need post-operative ERCP and stent insertion. On the other hand two cases only $(13.3 \%)$ of closure over stent experienced minimal bile leakage which stopped spontaneously by conservative treatment. Four cases $(26.6 \%)$ of Group (A) experienced wound infection, only two cases $(13.3 \%)$ in cases Group (B). One case in each group developed recurrent CBD stone. Three cases (20\%) of Group (A) need post-operative ERCP due to bile leakage not stopped by conservation, but nine of cases (60\%) of Group (B) need post-operative ERCP for stent removal. Five cases had spontaneous distal migration of stent, so not need ERCP and one case had proximal migration of stent in the CHD which need reexeploration and $\mathrm{T}$-tube insertion. One case (6.6\%) of Group (A) developed post-operative cholangitis versus two cases $(13.3 \%)$ of Group (B).

Two cases (13.3\%) of Group (A) developed post-operative abdominal pain versus three cases (20\%) of Group (B). There is no death in cases of Group (B), but one case of Group (A) has been died due to pre-operative cerebrovascular stroke, liver cirrhosis and portal hypertension which developed internal hemorrhage after four days of operation and reexeploration had been done and there was massive bleeding from the right branch of portal vein, repair with $3 / 0$ vicryl was done then the patient admitted in ICU and died after three days due to shock and chest infection as shown in Table (6).

Table (1): Demographic characters.

\begin{tabular}{llll}
\hline & Group A & Group B & $p$-value \\
\hline Mean age & $45.5 \pm 8.5$ & $40.5 \pm 10$ & 0.551 \\
Sex, M/F & $3 / 12$ & $4 / 11$ & 0.482 \\
Medical history: & & & 0.132 \\
CVS & 1 & 2 & - \\
DM & 2 & 3 & - \\
LC & 1 & 0 & - \\
\hline
\end{tabular}

Table (2): Clinical characteristics.

\begin{tabular}{|c|c|c|c|}
\hline & Group A & Group B & $p$-value \\
\hline Abdominal pain & $3 \quad(20 \%)$ & $7(46 \%)$ & 0.046 \\
\hline Jaundice & $14(93 \%)$ & $13(86 \%)$ & 0.281 \\
\hline Acute cholecystitis & $3(20 \%)$ & $4(26 \%)$ & 0.177 \\
\hline Acute pancreatitis & 0 & $2(13 \%)$ & - \\
\hline Cholangitis & 0 & $1 \quad(6.6 \%)$ & - \\
\hline
\end{tabular}

Table (3): Pre-operative biological characteristics.

\begin{tabular}{lllc}
\hline & Group A & Group B & $p$-value \\
\hline Leukocytosis & $3(20 \%)$ & $7(46 \%)$ & 0.021 \\
Raised TB & $14(93 \%)$ & $13(86 \%)$ & 0.261 \\
Raised DB & $14(93 \%)$ & $13(86 \%)$ & 0.493 \\
Raised ALP & $12(80 \%)$ & $12(80 \%)$ & 0.991 \\
Raised ENZ & $5(33 \%)$ & $7(46 \%)$ & 0.069 \\
Impaired PC & $11(73 \%)$ & $10(66 \%)$ & 0.182 \\
\hline
\end{tabular}

Table (4): Pre-operative radiological characteristics.

\begin{tabular}{|c|c|c|c|}
\hline & Group A & Group B & $p$-value \\
\hline $\mathrm{CBD}$ diameter in $\mathrm{mm}$ & $16 \pm 3(11-22)$ & $13 \pm 2(8-18)$ & 0.019 \\
\hline \multicolumn{4}{|l|}{ No of stones: } \\
\hline Single & $5 \quad(33 \%)$ & $3(20 \%)$ & 0.061 \\
\hline Multiple & $10(66 \%)$ & $12(80 \%)$ & 0.148 \\
\hline \multicolumn{4}{|l|}{ Size of stones: } \\
\hline Small* & $3(20 \%)$ & $4(26 \%)$ & 0.465 \\
\hline Large $*$ & $12(80 \%)$ & $11(73 \%)$ & 0.264 \\
\hline Stenting during ERCP & $13(86 \%)$ & $12(80 \%)$ & 0.118 \\
\hline
\end{tabular}

NB: Small stone means less than $1 \mathrm{~cm}$, large stone means more than $1 \mathrm{~cm}$. 
Table (5): Intraoperative characteristics.

\begin{tabular}{llll}
\hline & Group A & Group B & $p$-value \\
\hline Approach: & & & \\
$\quad$ Lap & $8(53.3 \%)$ & $2(13.3 \%)$ & 0.038 \\
$\quad$ Open & $7(46.6 \%)$ & $13(86.6 \%)$ & 0.042 \\
Operative time in m & $120 \pm 28$ & $125 \pm 20$ & 0.096 \\
Complete CBD clearance & 15 & 15 & 0.977 \\
Abdominal drain & 15 & 15 & 0.981 \\
\hline
\end{tabular}

Table (6): Post-operative characteristics.

\begin{tabular}{llll}
\hline & \multicolumn{1}{c}{ Group A } & \multicolumn{1}{c}{ Group B } & $p$-value \\
\hline - Hospital stay in days & $4 \pm 1.5(3-7)$ & $2 \pm 0.5(2-3)$ & 0.043 \\
- Bile leakage & $6(40 \%)$ & $2(13.3 \%)$ & 0.027 \\
- Wound infection & $4(26.6 \%)$ & $2(13.3 \%)$ & 0.032 \\
- Recurrent stones & $1(6.6 \%)$ & $1(6.6 \%)$ & 0.984 \\
- Post-operative ERCP & $3(20 \%)$ & $9(60 \%)$ & 0.022 \\
- Post-operative cholangitis & $1(6.6 \%)$ & $2(13.3 \%)$ & 0.189 \\
- Post-operative abdominal & $2(13.3 \%)$ & $3(20 \%)$ & 0.216 \\
$\quad$ pain & & & \\
- Mortality & 1 & 0 & - \\
\hline
\end{tabular}

\section{Discussion}

There is still some debate about how best to manage CBDS. One-stage treatment has the advantage to treat CBDS and cholecystectomy during a single operation [8] . Laparoscopic CBD exploration has been shown to be Feasible and equivalent to other means of treating stones in the CBD [9] However, the best method for choledochotomy closure remains unresolved [10]. Historically, Ttube has been used for biliary decompression and minimize the risk of bile leakage [11], provide an easy percutaneous access for cholangiography and extraction of retained stones [12].

In spite of these advantages, a specific morbidity related to T-tube usage is reported as accidental displacement [13], bile leakage, wound infection, cholangitis, prolonged hospital stay, restrict the patient's activity, risk for dehydration and electrolyte disturbance. Although PC may avoid complications of T-tube, there is no conclusive data favoring one technique over the other. Furthermore, secondary to instrumentation of the CBD and maneuvers for stone extraction, papilla could develop edema and increase biliary tree pressure, and the associated risk of bile Leakage. Insertion of biliary stent may be an alternative that can satisfy both conditions [14]. The use of primary duct closure not suitable for patients with severe acute biliary pancreatitis, acute pyogenic cholangitis, small CBD diameter or ampullary stenosis [15]. There are four requirements for a safe and successful PC of CBD are patent Vater's ampulla, complete removal of all intraductal calculi, absence of pancreatic pathology and meticulous suture of the duct [16].

In our study, there was no post-operative mortality in cases of intraoperative CBD stenting, but there was one case of PC died due to liver cirrhosis and portal hypertension and postoperative bleeding and shock. Two cases of intraoperative biliary stenting experienced minimal bile leakage which stopped spontaneously by conservation, but six cases of PC experienced bile leakage three of them stopped spontaneously, other three cases need ERCP and stent insertion. One of advantages of use of biliary stents is their distal migration without the need for a second procedure, which reduces the risk of complications and treatment expenses. However, the possibility of retention of biliary stent is present which necessitate endoscopic removal after six weeks.

Our study has some limitations, the number of patients included was small, there was no longterm follow-up and we did not study possible late complications, also the choledochoscope was sometimes not available and we use only intraoperative cholangiogram to confirm complete clearance of the bile ducts from stones. Despite the results and their statistical significance, the single study is a limitation. Large-scale randomized controlled trials are required to provide robust data on efficacy and safety of use of intraoperative bile stent drainage after choledocholithotomy in the future.

\section{Conclusion:}

A common bile duct closure after intraoperative biliary stent placement is safe and feasible method after choledocholithotomy in cases of CBD stone with failure of stone extraction by ERCP in suitable patients. Our results show benefits of this approach in terms of shorter hospital stay, less complications as biliary leakage, biliary stricture and lower associated costs.

\section{References}

1- KRATZER W., R.A. MASON and V. KACHELE: Prevalence of gallstones in sonographic surveys worldwide. $\mathrm{J}$. Clin. Ultrasound., 27 (1): p. 1-7, 1999.

2- SHOJAIEFARD A., et al.: Various techniques for the surgical treatment of common bile duct stones: A meta review. Gastroenterol. Res. Pract., 2009: p. 840208, 2009.

3- VERBESEY J.E. and BIRKETT D.H.: Common bile duct exploration for choledocholithiasis. Surg. Clin. North Am., 88: 1315, 2008.

4- KHALED Y.S., MALDE D.J., De SOUZA C., et al.: Laparoscopic bile duct exploration via choledochotomy 
followed by primary duct closure is feasible and safe for the treatment of choledocholithiasis. Surg. Endosc., 27: 4164-70, 2013.

5- SHEFFIELD K.M., HAN Y., KUO Y.F., TOWNSEND C.M., GOODWIN J.S. and RIALL T.S.: Variation in the use of intraoperative cholangiography during cholecystectomy. Journal of the American College of Surgeons, 214 (4): 668-79; discussion 679-81. Elsevier Inc. doi: 10.1016/j.jamcollsurg.2011.12.033, 2012.

6- HAIDER J., AZIZ A., KHAN L. and ALAM S.N.: Primary closure of common bile duct after open choledochotomy. J. Surg. Pak., 14: 173-5, 2009.

7- ESCALONA A., JARUFE N., IBÁÑEZ L., VIVIANI P., GARCÍA C., BENAVIDES C. and SALVADÓ J.: Prospective randomized study of T-tube versus biliary stent for common bile duct decompression after open choledocotomy, World J. Surg., Jul., 29 (7): 869-72. PMID: 15951939, 2005.

8- LU J., CHENG Y., XIONG X.Z., et al.: Two-stage vs single-stage management for concomitant gallstones and common bile duct stones. World J. Gastroenterol., 18: 3156-66, 2012.

9- BORIE F. and MILLAT B.: Laparoscopic treatment of common bile duct stones. Ann. Chir., 128: 722-7, 2003.

10- De ROOVER D., VANDERVEKEN M. and GERARD
Y.: Choledochotomy: Primary closure versus T-tube: A prospective trial. Acta Chir. Belg., 89: 320-4, 1989.

11- PAGANINI A.M., FELICIOTTI F., GUERRIERI M., TAMBURINI A., De SANCTIS A., CAMPAGNACCI R. and LEZOCHE E.: Laparoscopic common bile duct exploration. J. Laparoendosc. Adv. Surg. Tech., A 11: 391400, 2001.

12- QI WEI, HONG-JIE HHU, XIAO-YAN CAI, WEI Q., HU H.J., CAI X.Y., LI L.B. and WANG G.Y.: Biliary drainage after laparoscopic choledochotomy. World J. Gastroenterol., 10: 3175-8, 2004.

13- WILLS V.L., GIBSON K., KARIHALOOT C. and JORGENSEN J.O.: Complications of biliary T-tubes after choledochotomy. A.N.Z. J. Surg., 72: 177-80, 2002.

14- HOLDSWORTH R.J., SADEK S.A., AMBIKAR S., et al.: Dynamics of bile flow through the human choledochal sphincter following exploration of the common bile duct. World J. Surg., 13: 300-4, 1989.

15-HAIDER J., AZIZ A., KHAN L. and ALAM S.N.: Primary closure of common bile duct after open choledochotomy. J. Surg. Pak., 14: 173-5, 2009.

16- SORENSEN V.J., BUCK J.R., CHUNG S.K., FATH J.J., HORST H.M. and OBEID F.N.: Primary common bile duct closure following exploration: An effective alternative to routine biliary drainage. Am. Surg., 60: 451-4, 1994. 


\section{دراسة مقارنة بين الإصلاح الآولى للقناة المرارية الرئيسية

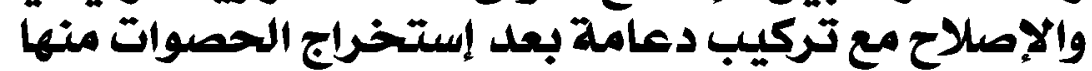

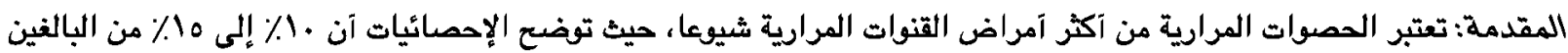

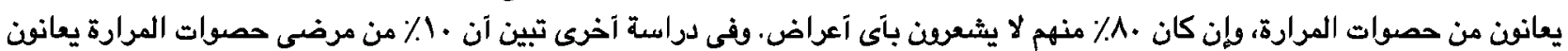

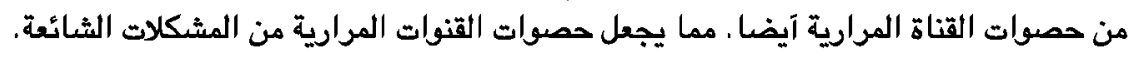

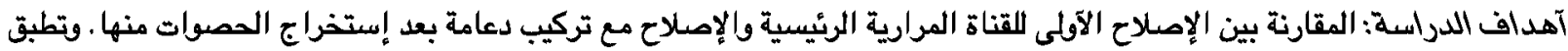

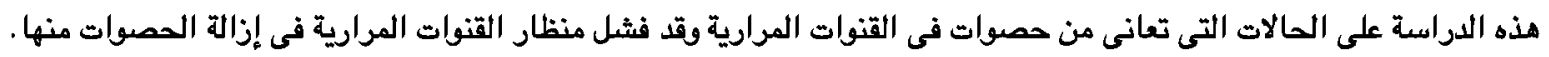
مجموعة الدراسة: هذه الدراسة تم تطبيقها على ثلاثين مريض يعانون من حصوات فى القناة المرارية وقد فشل منظار القنوات المرارية في إزالة الحصوات منها. وقد تم تقسيم المرضى إلى مجموعتين كل منها مكون من خمسة عشّر مريض كالتالى:

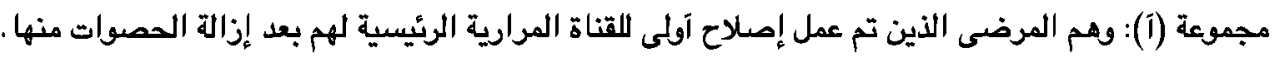
مجموعة (ب): وهم المرضى الذين تم عمل إصلاح للقناة المرارية الرئيسية لهم مع تركيب لدعامة فى القناة.

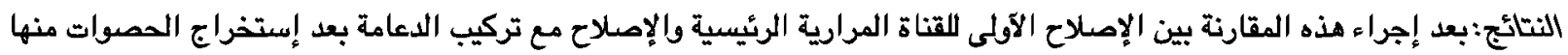

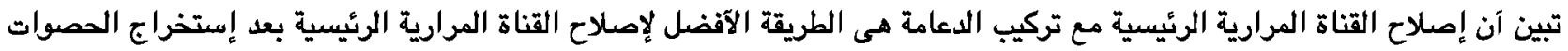
منها ، حيث آنه وجد آن هذه الطريقة مثاحة وسهلة التطبيق.

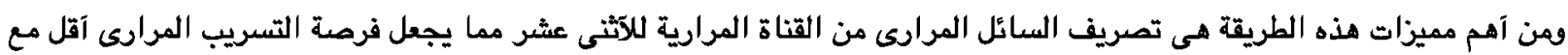

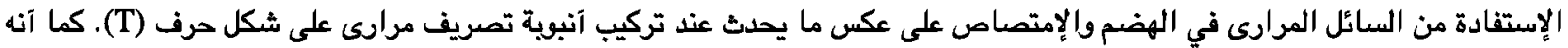

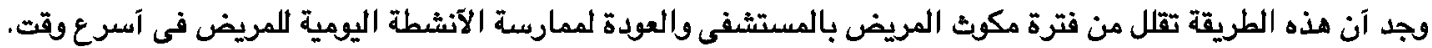

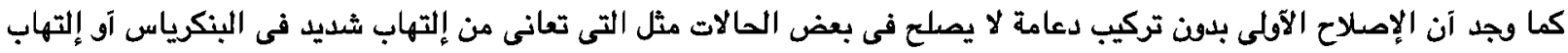

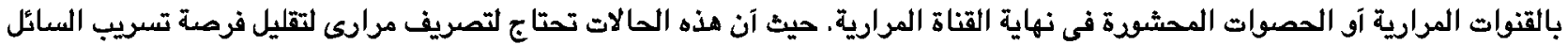
المرارى التى قد تحدث بعد العملية.

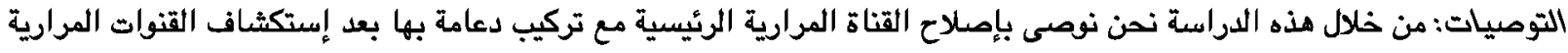
وإستخراج الحصوات منها وذلك فى الحالات التى تعانى من حصوات فى القناة المرارية ققد فشل منظار القنوات القيات المرارية فى إذالة الحصوات 